\title{
Schopenhauer's Rejection of Kant's Analysis of Cause and Effect
}

CHARLES NUSSBAUM

Emory University

Despite Schopenhauer's greatness as an original philosophical mind, and despite his sincere and profound admiration for Kant and the Critical philosophy, he remains a most unreliable interpreter of the work of Kant. Time and again in his criticisms of Kant's philosophy, both in its theoretical and practical aspects, Schopenhauer betrays a significant lack in his grasp of Critical principles. Nowhere is this lack more clearly evident than in his rejection, in The Fourfold Root of the Principle of Sufficient Reason. of the analysis and proof of the causal principle put forward by Kant in the Critigue of Pure Reason. ${ }^{2}$ This section of the Critique is extremely important, for not only does it contain some of the finest and most subtle argumentation in the entire work. but it also represents Kant's rebuttal of Hume's skeptical attack on the causal connection, an attack which was certainly instrumental in giving rise to the Critical philosophy itself. In a sense, Kant's causal argument epitomizes the Critical approach as a whole, and we should look very carefully at someone who, like Schopenhauer, claims kinship with Kant, but who at the same time rejects the Kantian analysis of cause and effect. We should try to be sure that such a rejection does not constitute a return to a pre-Critical dogmatism, albeit one expressed in the language of transcendental phllosophy.

My procedure in what follows will be to outline the problem of causality as it was bequeathed to Kant by his modern predecessors, particularly Descartes, Locke. and Hume, and then to look at the respective solutions to the problem provided by Kant and Schopenhauer. Einally, I will try to determine whether schopenhauer is justified in his rejection of Kant's solution, that is, whether he has properly understood Kant's argument, and whether he has something more adequate to offer in its place.

A treatment of causality is termed "dogmatic," when the necessity traditionally held to pertain to the causal connection is incorrectly grounded or assumed without adequate justification. The modern pre-critical causal dogmatism manifested itself in two ways. First, the causal connection was understood as a form 
of logical entallment, or logical ground and consequent. Second, the causal principle, that every change must have a cause, was held to be self-evident and a priori. In terms of the Cartesian epistemology which dominated the 17th century, the causal principle was an innate possession of the mind, along with other self-evident principles such as the principle of noncontradiction. For those of an empiricist persuasion who denled the existence of such innate ldeas, who held that the causal principle was not a priori and selfevident, but arose from experience (Locke): and who saw that the causal connection had to be understood as other than a relation of logical entailment, since contraxy connections could be concelved without contradictlon (Hume), the only apparently consistent courge was to relinguish the a priority and necessity of the causal principle, as well as the necessity of the connection between cause and effect. This step was in fact taken by Hume. The problem Kant set for himself was to preserve the necessity of the causal princtple and of the causal connection, without relying on any doctrine of Innate or self-evident principles, and without assimilating the causal connection to logical entailment.

Kant's solution to the problem takes the following form. Instead of a connection of logical entailment he ouggests a connection between representations within a gynthetic unity of apperception; and he postulates twelve a priorl categories, ostensibly derived from twelve forms of Iogical Judgment, as rules according to which this synthetic connection is to be made. As the logical fudgments bring lower (1ess general) concepts (representations) under the unity of a higher concept. so do the categories bring repregentations to the unity of apperception. "The same function," says Kant, "which gives unity to the various representations in a judgment also gives unity to the mere synthesis of various representations in an intuition; and this unity, in its most generai expression, we entitle the pure concept of the understanding." Causality 18, of course, Included among these categories. Since the categories are a priori, the connections they establish between representations are necessary, and not contingent, but also not analytic. In this way kant solves, to his own satiafaction, the dual problem of causality. Now, it is clear that the conception of the synthetic a priort solves (for Kant) the problem of the logical nature of the causal connection. What is not Bo clear is the way in which the notion of a category of the understanding 18 an advance over the notion of an innate idea. After all, if the category is a form of the understanding, why is it not something innate to the understanding? The difference is that Kant does not postulate these forms dogmatically, merely calling them "Belf-evident," but argues for them by means of a transcendental deduction. Having established the ide- 
ality of space and time in the "Transcendental Aesthetic" by caliing attention to the synthetic, yet a priori and apodictic nature of geometry and arithmetic. he argues for the categories as the only possible functions by which the manifold of representations intuited in space and time can be brought to the unity of apperception, the unity of the "I think." Since the causal category 18 established in this way, it can only be seen as a rule for the connection of representations. In addition, because the knowing self, the transcendental ego, is merely a focus of the formal unity of the "I think," it is not a substance which can be said to have innate possessions of any kind.

But the task of justification of the categories, while begun in the "Transcendental Deduction," can only be fully carried out in the "Analytic of Principles," after the schematism has been achieved, in which the categories are given spatial and temporal contextual meaning. In the "Analogies of Experience," the expanded arguments for the categories of relation, substance, cause, and reciprocity are ingeniously worked out as three interrelated rules for the ordering of representations in the time-series. Ordering here means objective ordering: while representations are said to be held together in a serial ordering by synthesis of Imagination (subjectively) in inner sense, the one objective series of events can only be established by means of rules determining experience for any observer. In the Analogies, the First (substance in general) grounds a single and continuous time-series, the Second (cause and effect) establishes the objective irreversible order of representations within this series, and the Third (reciprocity), by correlating reversible and irreversible series of representations establishes relative stasis and flux anong representations thereby establishing coexistence between empirical substances.

Now, what is really significant in Kant's Second Analogy argument is that he completely ignores the productive aspect of cause and interprets it purely as a rule for the necessary ordering of representations in time. Therefore, he has reversed the usual priority of cause and time: rather than regarding cause as arising out of the observation of a regular succession of events (Hume), Kant establishes cause as that which makes a regular succession concelvable in the first place. In this way Kant takes into account Hume's insight that the alleged productive connection between cause and effect, the "secret power," is a mystery, and completely hidden from view, and that all that can be observed is a regular succession." For Kant the causal category makes experience of regular succession possible, and is our means for distinguishing our subjective serial apprehension of representations from an objective series, one that is interpreted as alterations in the state of an object or objects. The causal category 
Is the basis upon which we distinguish objective empirical truth from the subjective play of fancy. But more importantly for our present purposes, it is also the basis for postulating the existence of an empirical object. As Kant himself puts it,

How, then does it come about that we posit an object for these representations, and so, in addition to their subjective reality as modifications, ascribe to them some mysterious kind of objective reality. Objective meaning cannot consist in the relation to another representation (of that which we desire to entitle object), for in that case the question arises, how this latter representation goes out beyond itself... only In so far as our representations are necessitated in a certain order as regards their time relations do they acquire objective meaning."

We can see that Schopenhauer's charge that "Kant - . did not clearly see that empirical perception $1 \mathrm{~s}$ brought about by the law of causality" is not just fied." Kant does insist, however, that only representations can be causally connected, because the empirical object is nothing other than a construct of representations. Yet a direct causal inference to a nonrepresentational object is just what Schopenhauer tries to accomplish. He otates that cause transforms "subfective oensation" into "objective intuitive perception": that the understanding grasps a given sensation as the effect of an object "outside the organism.": The fact that schopenhauer, in a supposed transcendental analysis, is already speaking in physiological terms should put us on our guard. Let us recali the two aspects of the dogmatic conception of cause, the a priority of the causal principle and the assumption of logical entaliment between cause and effect. Having observed Kant's method of dealing with them vis-a-vis the empiricist critigue, let us now see whether schopenhauer has something more adequate to offer in its place.

Schopenhauer construes cause and effect as one aspect of what he calls the principle of sufficient reason, which states that "nothing is without a ground or reason why it 18. " Although he takes his own formulation of the principle of sufficient reason from Wolff, it derives, of course, from the philosophy of Letbniz. Yet Schopenhauer's conception of the principle (in its causal aspect) has little in common with that of Leibniz. for it is clear that the principle is Schopenhauer's way of expressing the Kantian dictum that nothing in phenomenal experience can be unconditloned. But if Schopenhauex is to reject Kantian transcendental logic, the formal schema in terms of which Kant expresses such conditionedness, he must offer some 
other schema in terms of which causal explanation, as a species of the principle of sufficient reason, is to be concelved, since he follows Hume and Kant in recognizing that the relation of cause and effect is not one of logical ground and consequent.

There is also evidence that Schopenhauer does not really have an adequate conception of what transcendental logic is. For him, logic and reason are limited to what Kant had called "general logic," namely abstraction from particular sensible intuitions. Schopenhauer makes his position clear on many occasions, of which the following are good examples. In The Fourfold Root he 6 ays:

The only essential difference between human being and animal, which from time immemorial has been attributed to the faculty of reason (Vernunft), a very special cognitive faculty belonging exclusively to man, is based on the fact that he has a class of representations not shared by any animal. They are concepts and thus abstract representations, as opposed to the representations of intuitive perception, from which they are nevertheless drawn off."

In The World as W111 and Representation, he says much the same thing, holding that objects exist primarily only for perception, and that concepts are always abstractions from this perception. . . The essential nature of this faculty [of reflection] is the formation of concepts, 1.e.. of abstract non-perceptible representations, and this constitutes the sole function of our faculty of reason.. " il Because of this view of logic and reason the entire "Transcendental Analytic," depending as it does upon a revolutionary conception of logic, remains, for schopenhauer, a closed book. Rather than a logic of intensional concepts, transcendental logic is a logic of relations. and 1s, in effect, the formal framework of Kant's version of the coherence theory of truth. This is perhaps the most important epistemological development of the Critical philosophy and Kant's solution to the epistemological problems created by the development of Renaissance metaphysics that culminated in Descartes and Locke.

If the Renaissance development completely overturned the Aristotelian physics and metaphysics, the older logical and epistemological doctrines continued to hold sway. Thus while epochal changes in metaphysical thinking forced a schismatic separation between knowing mind and object to be known; entities, whether mental (spiritual) or material, continued to be conceived as substances with attributes, and knowledge continued to be thought of as an agreement between thought and object (with the notable exception of 
Berkeley). The Platonic metaphors of light and of clear. perception for intellectual apprehension (noesis) are evident in Descartes' appeal to clear and distinct ideas. But the IImitation of this approach in the context of a knowing self completely shut off from an alien world of lifeless matter becomes evident when we observe the phllosopher call upon God to invest his subjectively clear and distinct ideas with objective oignificance. Because of the aforementioned logical bias, relations were thought to be secondary in importance to attribution. The object of experience, as well as the self, were concelved as substances with inhering attributes. In the case of the object, such attributes were its qualities; In the case of the self. they were its thoughts (representations, Ideas, impresslons, etc.).

But we can see that this state of affairs left the knowing self certain only of its own immanent representations. As Locke says, "since the mind in all its thoughts and reasonings, hath no other immediate object but its own ideas, which 1 t alone does or can contemplate. It is evident that our knowledge is only conversant about them." 12 But then it is the case that "our knowledge therefore 19 real only so far as there is a conformity between our ideas and the reality of things. But what shall be here the criterion?"is it was Kant's insight to substitute for the correspondence conception a coherence criterion of truth, and for the substanceattribute model of the existent, the concept of a construct made up of representational elements in relation to one another. Objectivity (empirical truth) is secured by means of a formal standard, rules of synthesis (categories) of representations, and the manifold of representations as ordered according to these rules in public experience is necessarily the same for all observers and so unlversal.

It is precisely this coherence criterion of truth in terms of formal ordering of representations, $1 . e$.. the categoreal scheme, that allows Kant his empiricai realism in conjunction with a transcendental idealism. Because of the rule-governed ordering, empirical experience appears real. There is no quegtion within the consciousness of the experiencing subject as to whether any given bit of immanent material is real (objective) or not. because not only is its empirical reality included in 1 ts very form, and not referred to something outside immanent experience (Descartes, Locke), but this form differentiates the empirically objective from mental events which are empirically subjective, something Berkeley was not able to accomplish. As a conseguence, Berkeley reduced all experience to subjective Ideas within spiritual substance.

Kant's advance over Locke and Berkeley in establishing a true empirical realism within a transcendental Idealism is thus traceable to his transcendental 
logic and the categoreal scheme. But Schopenhauer, according to his own testimony, rejects Kant's doctrine of the categories: "I reject the whole doctrine of the categories," he says, "and number it among the groundless assumptions with which Kant burdened the theory of knowledge." He must therefore reject the transcendental logic, the transcendental deductions, and the Kantian coherence criterion of truth. But if he is to do so successfully, he must supply some other argument designed to show how the causal principle is prior to experience, and yet not dogmatically postulated as some sort of innate possession of the mind. He must also somehow establish the necessity of the causal connection. and must do so on grounds other than logical connection. And once Kant, by means of a modification of logic, had made an empirical "transcendence in immanence" possible there was no going back to the "problematic Idealism" of Descartes, or the "dogmatic idealism" of Berkeley. These are Kant's own characterizations in the "Refutation of Idealism." Hegel, we should point out, by means of a very different modification of logic, created a far more radical transcendence in immanence.

But if we ask whether schopenhauer has continued Kant's advance, we must answer in the negative, and conclude that he has merely provided old wine in new bottles. It is not sufficient to merely state in more or less Kantian language that cause as a species of sufficient reason 18 a form or function of the intellect. So stated, without anything like a transcendental deduction, it is difficult to see this as anything other than a dogmatic assertion. Scliopenhauer 8 answer to this is, of course, that because the principle of sufficient reason is a universal demand for proof in all instances, one cannot demand that it be proven." This may be correct. But that does not absolve one from the task of having to specify for a given body of explanation what is to count as adeguate proof and what is not. Every occurrence demands a search for a cause. Locke and Hume admit this. The problem is to determine the nature of this demand and how we can know that the demand has been met.

The account Schopenhauer does give of the function of the causal principle seems to be a reversion to an older conception. His doctrine that subjective sensation 18 changed into objective perception through application of the causal principle does not appear to be different in essentials from Locke's contention that judgment "alters the appearances into their causes."I Yet it is this contention of Locke that is one of Hume's principal targets, for he states in the Treatise: "even after we distinguish our perceptions from our objects, |it| will appear presently, that we are still incapable of reasoning from the existence of one to the other."I' But Schopenhauer has stated in appar- 
ent agreement with kant, that the law of causality refers exclusively to the appearance and disappearance of states of objects in time. "It is wrong to call the objects, not the state, the cause." "It is only when my understanding passes from the sensation to the cause thereof that it constructs for itself a body having the properties of solidity, impenetrability, and hardness." Kant, on the other hand, carefully distinguishes between substances as the source of action in appearances, and cause and effect as connecting representations. "Causality leads to the concept of action, this in turn to the concept of force, and thereby to the concept of substance." 20 Such theorizing is an extension of the concept of cause, and as the "empirical criterion" of a substance it has no place in pure transcendental analysis. Causality must be properiy grounded before empirical concepts such as force or action are introduced.

When Schopenhauer does speak of the connection of representations, he merely states that "al i our representations stand to one another in natural and regular connection that in form is determinable a prior1." Now what sort of "form" is this? It $1 \frac{a}{8}$ evident that Schopenhauer wishes to assert, with Kant, a synthetic a priori connection between representations. Büt what Ig his formal schema? How is such synthetic connection established? Since he preemptively dismisses Kant's transcendental unity of apperception as "a very strange thing strangely described," Kant's argument for cause and effect as one of the functions by means of which ouch unity within a Bynthetically connected manifold is achieved 18 not avallable to him. ${ }^{22}$ He cannot, as does Kant, argue for a category of cause and effect as a necessary presupposition of a unified fleld of experience, and so of anything that can be reasonably termed experience at all. This is the significance of a "transcendental deduction," and only in this somewhat weakened sense, compared to the earlier dogmatiom, are the categorles established a prior1. But schopenhauer appears to offer no argument Justifying the principle of sufficient reason other than an appeal to alleged self-evidence, or to some sort of claim as to the way the "mind" in Its essential nature operates. All he really supplies is a recyciling of the Cartesian dogmatism; and he lays hands upon the words 'transcendental' and a priort as if they were talismans invested with magicai expianatory powers.

Furthermore, for Schopenhauer 'transcendental' seems to mean merely the appearance of the transcendent, the thing-in-itsel $\bar{F}$, and thus becomes identified with the phenomenal. But it is just the form of the phenomenai, and not the phenomenon itself. As form, it is not abstracted from the observation of the function of the mind, but is a framework in terms of which the 
mind is to be understood in a functional sense. Transcendental logic is not a set of laws according to which the understanding must function; rather it is the understanding itself. The understanding does not exist apart from these rules, as something from which they can be abstracted, or to which they can be applied. Kant does say, it is true, that "the understanding does this." or "the imagination does that." But he cannot be speaking literally, for the ontological status of these "faculties" is problematical. If they are noumenal. how can we know anything about them; if phenomenal, they themselves are mere appearance, and cannot explain appearance. Kant must therefore be using the psychological "faculty" language as a model to facilitate understanding of the formal structure upon which his argument realiy depends. The transcendental ego is not an existent entity in any sense. Transcendental idealism, we can therefore see, is a subtle and tricky formulation. As a formal construct of mind it differs fundamentally from the metaphysical idealisms that had gone before, and great care must be taken to keep the transcendental and the empirical selves, or "egos," separate.

Einally, Schopenhauer's adoption of the Kantian distinction between phenomenon and thing-in-itself can be seen to create additional problems for him. By interpreting the thing-in-itself as will, Schopenhauer is forced to reduce the empirical world and the empirical self to mere appearances of the will. The world is the way the will appears under the forms of intellect; but because of the conflation of the empirical and transcendental selves, this intellect and 1 ts forms are themselves merely appearance. Recognizing the unteriability of the concept of soul or spiritual substance of Descartes, Locke, and Berkeley, but rejecting Kant's conception of the transcendental self as a formal unit, Schopenhauer has no alternative but to see the knowing self either as empirical or as thing-in-itself. In a sense he does both: the intellect is in actuality the will-to-know, and only as represented and objectified, the brain. But the will-to-know cannot be directly experienced; it can only be lived. As subjectively observed through introspection it is also phenomenon. Therefore both intellect as subjectively experienced and brain as objectively perceived are phenomena. "Matter is the representation of the intellect; the intellect is that in the representation of which alone matter exists. Both together constitute the world as representation, which 1 s precisely Kant's phenomenon, and consequently something secondary. What is primary is that which appears, namely the thing-in-itself, which we shall afterwards learn to recognize as the will." 3 But if the intellect is phenomenon its forms are not really transcendental, belonging to another or- 
dex; they are phenomenal, and as such, they cannot establish themselves, but are swallowed up in illusion.

Schopenhauer's position, however is self-defeating: the work of the understanding, equated with the functioning of the brain, is presented both as conditioning experience, and as appearance itself. It is as if Schopenhauer took too literally Kant's psychological language in the First Edition "Transcendental Deduction" and took kant to be actually describlng the functioning of the mind in a paychological sense, or of the thinking organ, the brain, In a physiological sense, rather than presenting a heuristic model. it is, of course, well known that schopenhauer greatly preferred the lot Edition to the 2nd. When criticluing Kant's conception of a moral law in The Basis of Morality Schopenhauer says "1f. . . his alleged moral law originates a priort in our head, it must likewige be only a form of the phenomenon." We clearly see here Schopenhauer's refusal (or inability) to separate the transcendental from the empirical subjective. The transcendental a priori does not originate "in our head": on the contrary, our head and brain, with their empirIcal contents, orlginate within it.

Consequently Schopenhauer's Idealism is strangely perverse: on the one hand it is dogmatic, in that it posits without justification innate forms that are supposed to pertain a priort to the knowing self; but on the other hand $1 \mathrm{t} 1 \mathrm{~s}$ ephemeral, because the knowing self and its functions are phenomenal, and do not really attain transcendental status. Although Schopenhauer has rejected the metaphysical conception of spir1tual substance. In which thoughts as representations or Ideas "Inhere," he has not provided a new conception of mind at all, as did Kant and Hegel. Rather, he has merely substituted a metaphysical substratum of energy as will. for the old metaphysics of substance. But mind, now degraded to mere phenomenon, functions in a way that reverts to the older conceptions of Descartes and Locke, amalgamating the innate possession doctrine of the former with the more empirical tendencies of the latter. But the Influence of Berkeley. whom Schopenhauer admired, is discernible as well, for unlike Descartes and Locke, Schopenhauer regards primary as well as secondary qualities of objects as "subjective." Schopenhauer repeatedly encourages the following misleading comparison between Locke and Kant:

- . Just as Locke clatmed for the organs of sense all that comes into perception or apprehension by means of sensation. in order to deny it to things in themseives, so Kant, with the same purpose and pursuing the same path, showed everything that makes real perception possible, namely space, time, and causality to be brain function. is 
Schopenhauer goes on to say: "He [Kant] refrained, however, from using this physiological expression." One would hope so!

Because his argument is not really transcendental, and because his approach is so thoroughly. un-Critical, Schopenhauer is Kantian only in so far as he takes over the conception of phenomenon and thing-in-itself. But his adoption of the Kantian terminology has served to render his entire enterprise self-defeating: for he is forced, as Locke, Berkeley, and Descartes were not, to regard intellect and reason themselves as phenomenal. But this calls his whole philosophy as a rational account into question; and even if we apply a "throw away the ladder once one has reached the goal" interpretation, all Schopenhauer tells us seems to be reduced to appearance and illusion. But perhaps, given his predilection for Eastern thought, he did mean something like this. And if we take seriously the dialectical reversal with which he ends the first Volume of The World as WIII and Representation, he may have truly believed ali rational apprehension to be illusion, and the real to be the "Prajna-Paramita," the "beyond all knowledge" of the Buddhists."

NOTES

'Arthur Schopenhauer, The Fourfold Root of the Principle of Sufficient Reason, trans. Payne, (LaSalie: Open Court, 1974).

2Immanuel Kant, Critlque of Pure Reason, trans. Kemp Smith, (New York: St. Martin's Press, 1965).

'Kant, Critique, $A 79=B 104$.

Ibid. , A195=B240, $A 197=B 242$.

'David Hume, An Enguiry concerning Human Understanding. Section IV, Part II, from The English philosophies from Bacon to M111, ed. Burtt, (New York: Modern Library, 1939), p. 603 .

'Kant, Critique, $A 197=B 242$. 115.

'Schopenhauer, Fourfold Root, Ch. IV, Sec. 21, p.

Ibid.. Ch. IV, Sec. 21, pp. 77-78.

'Ibid., Ch. I, Sec. 5, P. 6. 
"Ibid., Ch. V, Sec. 25, p. 145 .

"Schopenhauer, The World as W11l and Representation, Vol. I, trans. Fayne, (New York: Dover, 1969). Appendix: Criticism of the Kantian Philosophy, p. 448 .

$12 J o h n$ Locke, An Essay concerning Human Understanding, Book IV, Ch. I, p. 317, from Burtt, ed.

"Ibid., Book IV, Ch. IV, p. 344 . 452.

"Schopenhauer, The World, Vol. I, Appendix, p. 32.

"schopenhauer, Fourfold Root, Ch. II, Sec. 14, p.

"Locke, Essay. Book II, Ch. IX, p. 274.

'Hume, A Treatige of Human Nature, (Baltimore: Penguin Books, 1969), Bk. I, Part IV, Sec. II, p. 244. 55.

"Schopenhauer, Fourfold Root, Ch. IV, Sec. 20, p.

"Ibid.. Ch. IV, Sec. 21, p. 81.

"Kant, Crit1que, A204=B249.

42.

'Schopenhauer, Fourfold Root, Ch. III, Sec. 16, p. 451 .

"2chopenhauer, The World, Vol. I, Appendix, p.

"Ibid., Vol. II, Ch. I, p. 16.

"Schopenhauer, On the Basis of Morality, trans. Payne, (Indianapolis: Bobbs-Merrili Co., 1965). II. Sec. 6, p. 65.

"Schopenhauer, The World, Vol. II, Ch. 22, p. 285.

2"Ib1d.. Vol. II, Ch. 22, p. 285.

'Ibid., Vol. I, Book IV, Sec. 71, p. 412. 